\title{
MEDICINA VETERINÁRIA
}

\section{FORNECIMENTO DE PLASMA SUÍNO SPRAY-DRIED DILUÍDO EM ÁGUA ACIDIFICADA PARA LEITÕES COM SINTOMAS DE CIRCOVIROSE NO INÍCIO DA FASE DE CRESCIMENTO E TERMINAÇÃO}

\author{
ARMANDO LOPES DO AMARAL ${ }^{1}$, NelSON MORÉs ${ }^{1}$, JANICE ReIS CIACCI ZANELLA $^{1}$, ARLEI \\ COLDEBELLA $^{1}$, LUIS FERNANDO SARMIENTO RANGEL ${ }^{2}$ \\ ${ }^{1}$ Pesquisadores da Embrapa Suínos e Aves, Centro Nacional de Pesquisa de Suínos e Aves, \\ Concórdia, SC - amaral@ cnpsa.embrapa.br \\ ${ }^{2}$ Mestrando, Escola Superior de Agricultura Luiz de Queiroz (ESALQ), Piracicaba, SP
}

RESUMO

\begin{abstract}
Estudou-se o efeito do plasma suíno spray-dried ultrafiltrado $\left(\mathrm{AP} 920^{\circledR}\right)$ diluído em água de bebida acidificada com ácido Selko $^{\circledR}-\mathrm{pH}$, para recuperação de leitões com sinais clínicos da Síndrome Multissistêmica do Definhamento (SMD). O experimento foi conduzido em oito unidades de terminação de uma agroindústria de Santa Catarina com confirmação da SMD pela histopatologia, imunoistoquímica (IHQ) e reação em cadeia da polimerase. As granjas manejavam as instalações no sistema de todos dentro todos fora com vazio sanitário de sete dias entre lotes. O estudo foi iniciado aos 14 dias após o alojamento dos leitões e finalizado 42 dias depois. O experimento foi delineado aleatoriamente por peso e sexo com dois tratamentos: $\mathrm{T}_{1}$ (controle) com água à vontade e $\mathrm{T}_{2}$ (tratado) com solução composta por $250 \mathrm{~g}$ de plasma suíno em $10 \mathrm{~L}$ de água de bebida acidificada com $12 \mathrm{~mL}$ de ácido. Os animais foram distribuídos em duas baias na mesma instalação com nove ou dez leitões por baia, sendo uma controle e a outra
\end{abstract}

tratado. As variáveis avaliadas foram: $\mathrm{pH}$ da água e da solução; peso individual e condição clínica dos leitões; consumo das soluções no período de 0 a 14 dias, consumo de ração e conversão alimentar; taxa de mortalidade, exame histopatológico e imunoistoquímico dos animais que morreram. Os leitões do $\mathrm{T}_{2}$ apresentaram melhora clínica nos 14 dias e melhor conversão alimentar nas avaliações aos 28 dias de experimento. Nos dados de desempenho, os exames histológicos e de imunoistoquímica não apresentaram diferença estatística entre os tratamentos, exceto para conversão alimentar em que o grupo que recebeu plasma + ácido foi melhor que o controle, com probabilidade de 0,0372 para o efeito principal. Conclui-se que os leitões com sinais da SMD que receberam plasma em água acidificada apresentaram melhora clínica nos 14 dias de experimento em relação aos controles e melhor conversão alimentar nos primeiros 28 dias de experimento.

PALAVRAS-CHAVE: circovirose; plasma suíno; síndrome multissistêmica do definhamento; suíno.

\section{SUPPLY OF PORCINE SPRAY-DRIED PLASMA DILUTED IN ACIDIC WATER TO PIGS AFFECTED BY POST-WEANING MULTISYSTEMIC WASTING SYNDROME (PMWS) AT THE BEGINNING OF FINISHING}

\section{ABSTRACT}

The effect of the spray-dried porcine plasma diluted in drinking acidified water for recovery of piglets with clinical signs of the Post-Weaning Multisystemic Wasting Syndrome (PMWS) was studied. The experiment was conducted in eight finishing units of an agroindustry of Ci. Anim. Bras., Goiânia, v.12, n.4, p. 681 - 686, out./dez. 2011
Santa Catarina State, Brazil, with positive diagnosis of PMWS by histopathology, immunohistochemistry (IHC) and polimerase chain reaction (PCR). The study was initiated around 14 days after the lodging of the piglets and concluded 42 days later. The experiment was 
randomly designed by weight and sex with two treatments: $\mathrm{T}_{1}$ - water ad libitum as a control group and $\mathrm{T}_{2}$ - a solution constituted of porcine plasma (250g) in drinking acidified water (10L). The animals were distributed into two batch pens in the same facility with nine or ten piglets per pen, being one the control pen and the other one the treated pen. The following variables were evaluated: $\mathrm{pH}$ of water and solution; individual weight and clinical conditions of the piglets; solution intake within the period from 0 to 14 days, feed intake and feed conversion rate; mortality rate, histopathology and IHC analysis of the animals that died. The piglets of $\mathrm{T}_{2}$ presented clinical improvement during the 14 days of the experiment and a better feed conversion rate at 28 days of the experiment. Performance data did not show statistical difference between the treatments, except for feed conversion in the group that received $\mathrm{T}_{2}$, which was better than control group $\left(T_{1}\right) \mathrm{p}=0.0372$ for the main effect. It was concluded that piglets with PMWS signs, which received plasma in acidified water, presented clinical improvement during the 14 days of the experiment, in comparison with control animals and better feed conversion ratio at the first 28 days of the experiment.

KEYWORDS: porcine circovirus associated diseases; porcine plasma; post-weaning multisystemic wasting syndrome; swine.

\section{INTRODUÇÃO}

Nos últimos anos, surgiram/recrudesceram algumas patologias nas criações industriais de suínos (EMERGING..., 2011). Entre elas, destacam-se várias manifestações clínicas da síndrome circovirose suína causada pelo circovírus suíno tipo 2 (PCV2), sendo a Síndrome Multissistêmica do Definhamento (SMD) a mais importante (SEGALÉS, 2011). A SMD afeta, predominantemente, leitões entre oito a 12 semanas de idade e caracteriza-se clinicamente por apatia, dispnéia, emagrecimento rápido, anemia/icterícia, manchas avermelhadas na pele e aumento do tamanho dos linfonodos (ZANELLA et al., 2003). Atualmente, as síndromes associadas ao PCV2 são responsáveis por grandes perdas econômicas na suinocultura, devido à refugagem e mortalidade dos leitões e também pelo aumento no uso de antimicrobianos e desinfetantes (HARDING et al., 1998). O PCV2 persiste no organismo do suíno durante muito tempo após a infecção, mesmo sem sinais clínicos, e isso é importante no mecanismo da transmissão, mantendo a doença no rebanho (KIM et al., 2003). O controle da SMD é difícil e baseia-se na identificação e correção de fatores de risco que favoreçam a ocorrência da doença (MADEC et al., 1999).

O plasma suíno ultrafiltrado (AP920 ${ }^{\circledR}$ ) seco por spray dry tem sido adicionado às dietas para melhorar o desempenho (COFFEY \& CROWELL, 2001; ARAÚJO, 2002) e a saúde de leitões infectados por Escherichia coli e rotavirus (HARREL et al., 2000). Tal efeito pode ser devido a anticorpos presentes no produto (VAN DIJK, 2002). O objetivo deste trabalho foi testar o efeito do plasma suíno spray-dried ultrafiltrado $\left(\mathrm{AP} 920^{\circledR}\right.$ ), diluído em água de bebida acidificada, para recuperação de leitões com sinais clínicos da SMD no início do crescimento e terminação.

\section{MATERIAL E MÉTODOS}

$\mathrm{O}$ experimento foi conduzido em oito unidades de terminação (UT) da parceria de uma agroindústria de Santa Catarina (SC), no período de novembro/2004 a janeiro/2005, com capacidade de alojar 400 a 600 animais por terminador e com histórico de ocorrência de circovirose no $1^{\circ}$ mês de alojamento nos lotes anteriores. Cada UT alojou os leitões no mesmo dia, com 60 a 70 dias de idade, peso médio aproximado de $22,0 \mathrm{~kg}$ e manejava as instalações em lotes com vazio sanitário entre eles de no mínimo 7 dias. De cada UT que apresentava leitões com sinais clínicos da SMD na primeira semana de alojamento, foram sacrificados e necropsiados dois leitões com sinais da doença para confirmação do diagnóstico pela histopatologia, imunoistoquímica (IHQ) e reação da cadeia da polimerase (PCR) para o PCV2. Somente as UTs com confirmação da SMD e que tinham mais leitões com sinais da doença no lote foram incluídas no estudo.

O estudo foi iniciado aos 14 dias após o alojamento dos leitões e finalizado 42 dias depois. O experimento foi delineado aleatoriamente por peso e sexo dos suínos e em dois tratamentos $\left(\mathrm{T}_{1}\right.$ e $\left.\mathrm{T}_{2}\right)$. Os tratamentos foram distribuídos em duas baias na mesma instalação, com nove ou dez leitões em cada baia, dependendo do número de animais que apresentavam sinais clínicos da doença na UT. Os tratamentos foram $\mathrm{T}_{1}$ (controle) com água à vontade e $\mathrm{T}_{2}$ (tratado) com $250 \mathrm{~g}$ de plasma suíno (AP920 ${ }^{\circledR}$ composição: proteína bruta $78 \%$, gordura $0,3 \%$, fibra bruta $0,5 \%$, cinza $8,5 \%$, energia digestiva 4108 $\mathrm{kcal} / \mathrm{kg}$, energia metabolizada $3906 \mathrm{kcal} / \mathrm{kg}$, lysina $6,8 \%$ e metionina $0,7 \%$ ) em $10 \mathrm{~L}$ de água acidificada com $12 \mathrm{~mL}$ de ácido Selko ${ }^{\circledR}-\mathrm{pH}$ (composição: ácido 
fórmico 63\% e ácido acético 12\%) para atingir o $\mathrm{pH}$ final mais próximo de 4,5. As respectivas soluções foram preparadas duas vezes ao dia pelo produtor, mantidas em recipiente plástico graduado com capacidade para $10 \mathrm{~L}$ e fornecidas à vontade aos leitões durante 14 dias, em bebedouro de PVC de $0,8 \mathrm{~m}$ de comprimento e $0,15 \mathrm{~m}$ de diâmetro. Nesse período foi suspenso o fornecimento de água dos bebedouros durante o dia e liberado à noite.

Os animais em teste não foram medicados por via injetável e receberam a ração padrão da empresa à vontade. As variáveis avaliadas foram: $\mathrm{pH}$ da água de cada UT no início do experimento; $\mathrm{pH}$ das soluções no inicio do experimento, utilizando-se um potenciômetro; peso individual e condição clínica dos leitões nos dias 0, 14, 28 e 42 do experimento; consumo das soluções nos períodos de 0-14 dias, consumo de ração e conversão alimentar nos períodos de 0-14, 15-28 e 29-42 dias de experimento; causa da morte baseada na necropsia, exame histopatológico e IHQ dos animais e taxa de mortalidade. Para cada leitão do $\mathrm{T}_{2}$ foram calculados a quantidade e o custo do AP920 ${ }^{\circledR}$ fornecido (na época do estudo o custo médio ao produtor do AP920 ${ }^{\circledR}$ foi de R\$ $10,00 / \mathrm{kg}$ e do Ácido Selko ${ }^{\circledR} \mathrm{R} \$$ $7,20 / \mathrm{L})$.

A análise dos dados de desempenho foi realizada utilizando-se a teoria de modelos mistos, considerando-se os efeitos de granja, tratamento e período experimental, e 16 estruturas de matriz de variâncias e covariâncias, por meio do procedimento MIXED do SAS Instituto Inc. (2001), utilizando-se a macro proposta XAVIER (2000). A matriz de covariâncias foi escolhida com base no critério de informação de Akaike (AIC). Para as avaliações clínicas foi usado o teste de $\chi^{2}$.

\section{RESULTADOS E DISCUSSÃO}

$\mathrm{O} \mathrm{pH}$ da água fornecida aos animais nas UTs variou de 5,1-7,0. Mesmo tratando-se de água pura, foi registrada variação acentuada entre as granjas, o que não era esperado; entretanto, o pH da solução fornecida aos leitões do $\mathrm{T}_{2}$ (plasma + ácido) variou entre 4,40-4,94, mostrando que a adição do ácido manteve a solução estável (Figura 1). A quantidade média de solução ou de água consumida pelos animais em cada UT foi maior no grupo que consumiu a solução com plasma $\left(\mathrm{T}_{2}\right)$ em comparação com o controle $\left(\mathrm{T}_{1}\right)$, mas houve uma variação acentuada entre as UTs, especialmente no $\mathrm{T}_{2}$ (Figura 2). Cada leitão do $T_{2}$ consumiu em média $56,34 \mathrm{~L}$ da solução com plasma mais ácido, totalizando $1,41 \mathrm{~kg}$ de plasma e 67,6 mL de ácido. Isso implicou um custo adicional no tratado de $\mathrm{R} \$ 14,1$ de plasma e $\mathrm{R} \$$ 0,49 de ácido por leitão.

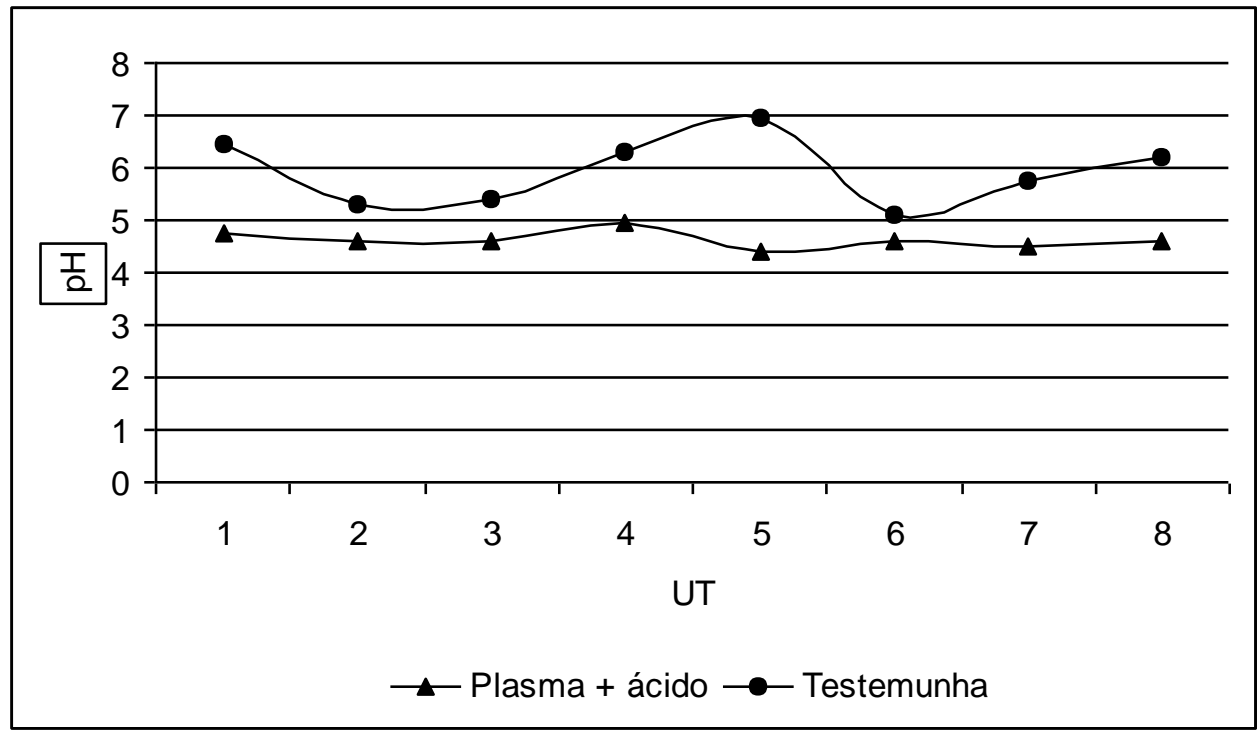

Figura 1 - pH da solução de plasma + ácido e da água nas 8 UTs avaliadas. 


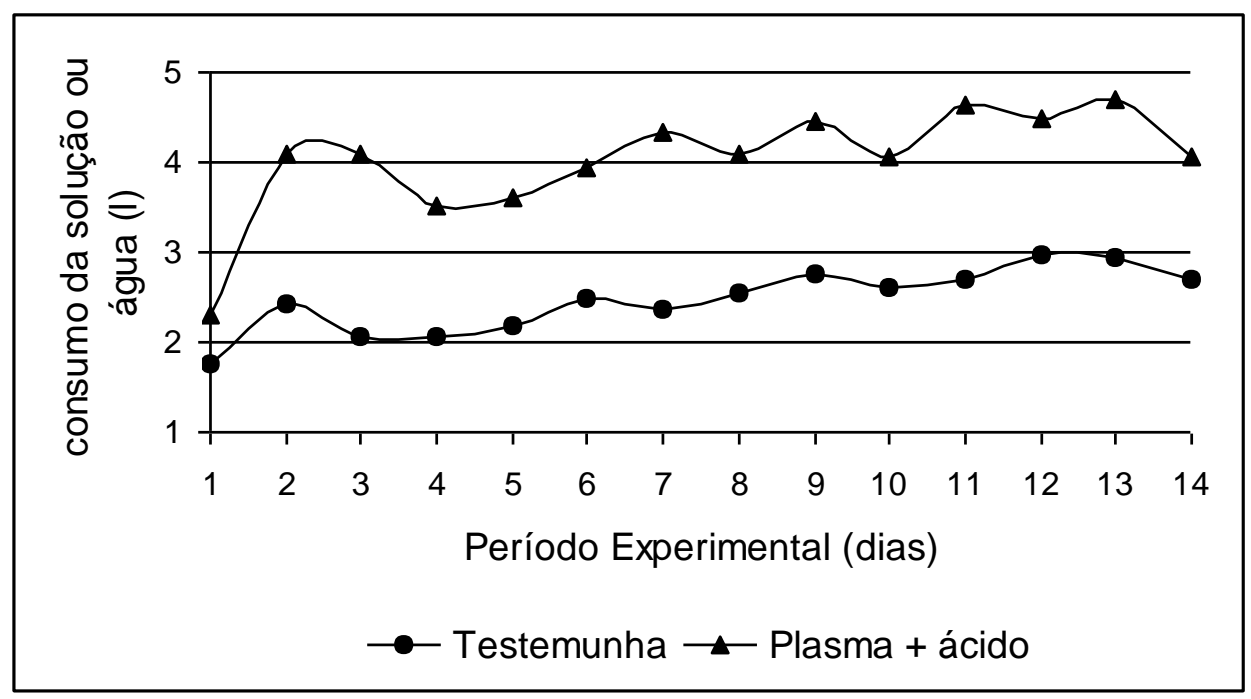

Figura 2 - Consumo médio diário individual da solução ou água por dia nos primeiros 14 dias do experimento.

A análise inicial por meio da macro proposta de XAVIER (2000) levou à escolha da matriz de variâncias e covariâncias do tipo simetria composta heterogênea para avaliação de todas as variáveis de desempenho, com base no menor valor de AIC. Não houve diferença estatística entre os tratamentos, exceto para conversão alimentar, pois o grupo que recebeu plasma + ácido foi melhor que o testemunha, com probabilidade de 0,0372 para o efeito principal (Tabela 1). Contudo, houve interação significativa entre tratamentos e período experimental $(\mathrm{p}=0,0594)$ para conversão alimentar. $O$ teste $F$ para $o$ desdobramento da análise de tratamento dentro de período experimental indicou diferença significativa entre tratamentos apenas na conversão alimentar nos períodos de $14(\mathrm{p}=0,0286)$ e $28(\mathrm{p}=0,0323)$ dias do experimento (Tabela 2). A inclusão de plasma spray dry na dieta de leitões desmamados estimula o consumo de alimento, aumenta a taxa de ganho de peso e melhora a conversão alimentar (COFFEY \& CROMWELL, 2001).

Os resultados dos exames clínicos estão apresentados na Tabela 3. No início do experimento, não houve diferença entre os tratamentos nas avaliações clínicas realizadas. Na avaliação realizada aos 14 dias de experimento houve diferença significativa para as variáveis estado corporal $(\mathrm{p}=0,0103)$, anemia e icterícia $(\mathrm{p}=0,0231)$, constatando-se maior número de leitões com definhamento e palidez/icterícia no grupo controle $\left(\mathrm{T}_{1}\right)$. Isso, provavelmente foi devido ao consumo do plasma pelos leitões no período, pois, nas demais avaliações em que eles não receberam plasma, o efeito não foi observado. No exame realizado aos 28 dias de experimento foi constatada diferença no aspecto das fezes $(\mathrm{p}=0,0116)$ e lesão de pele $(\mathrm{p}=0,0045)$, com maior ocorrência de leitões com diarréia e lesões de pele no $\mathrm{T}_{2}$. Uma explicação possível para a maior ocorrência de diarréia nos leitões que receberam plasma pode ser o aumento na ingestão de proteínas (MORÉS et al., 1990). Aos 42 dias de experimento não houve diferença entre os tratamentos em todas as avaliações clínicas realizadas.

Tabela 1- Níveis descritivos de probabilidade da análise de modelos mistos usando a estrutura de matriz de variâncias e covariâncias do tipo simetria composta heterogênea

\begin{tabular}{lccc}
\hline \multirow{2}{*}{ Causas de variação } & \multicolumn{3}{c}{ Pr>F } \\
\cline { 2 - 4 } & Peso vivo & Consumo de ração & Conversão alimentar \\
\hline Granja & $<, 0001$ & 0,0051 & 0,5716 \\
Tratamento & 0,2020 & 0,8071 & 0,0372 \\
Período & $<, 0001$ & $<, 0001$ & 0,1748 \\
Período $\times$ tratamento & 0,1374 & 0,8781 & 0,0594 \\
\hline
\end{tabular}


Tabela 2- Nível descritivo de probabilidade para o efeito de tratamento dentro de período experimental, para conversão alimentar

\begin{tabular}{lcc}
\hline Efeito & Idade & Pr $>$ F \\
\hline Tratamento dentro de 14 dias & 14 & 0,0286 \\
Tratamento dentro de 28 dias & 28 & 0,0323 \\
Tratamento dentro de 42 dias & 42 & 0,1890 \\
\hline
\end{tabular}

Tabela 3- Avaliação clínica para a SMD nas diferentes etapas do experimento (acumulado das 8 granjas)

\begin{tabular}{|c|c|c|c|c|c|c|c|c|c|c|c|c|c|}
\hline \multirow{2}{*}{ Variáveis } & \multirow{2}{*}{ Classificação } & \multicolumn{3}{|c|}{ Inicio do experimento } & \multicolumn{3}{|c|}{14 dias } & \multicolumn{3}{|c|}{28 dias } & \multicolumn{3}{|c|}{42 dias } \\
\hline & & $\mathrm{T} 1$ & $\mathrm{~T} 2$ & $\mathrm{P}^{*}$ & $\mathrm{~T} 1$ & $\mathrm{~T} 2$ & $\mathrm{P}^{\mathrm{a}}$ & $\mathrm{T} 1$ & $\mathrm{~T} 2$ & $\mathrm{P}^{*}$ & $\mathrm{~T} 1$ & $\mathrm{~T} 2$ & $\mathrm{P}^{*}$ \\
\hline \multirow{2}{*}{$\begin{array}{l}\text { Estado } \\
\text { Corporal }\end{array}$} & 1. Normal & 0 & 0 & \multirow{2}{*}{1,000} & 37 & 53 & \multirow{2}{*}{$0,0103 *$} & 43 & 42 & \multirow{2}{*}{0,9474} & 46 & 43 & \multirow{2}{*}{0,6640} \\
\hline & 2. Definhamento & 74 & 74 & & 33 & 19 & & 25 & 25 & & 20 & 22 & \\
\hline \multirow{2}{*}{ Apatia } & 1. Normal & 61 & 58 & \multirow{2}{*}{0,5344} & 48 & 54 & \multirow{2}{*}{0,3945} & 52 & 49 & \multirow{2}{*}{0,6552} & 58 & 56 & \multirow{2}{*}{0,7690} \\
\hline & 2. Apático & 13 & 16 & & 22 & 18 & & 16 & 18 & & 8 & 9 & \\
\hline \multirow{2}{*}{$\begin{array}{l}\text { Anemia } \\
\text { Icterícia }\end{array}$} & 1. Normal & 27 & 24 & \multirow{2}{*}{0,6038} & 8 & 19 & \multirow{2}{*}{$0,0231 *$} & 30 & 31 & \multirow{2}{*}{0,8017} & 27 & 34 & \multirow{2}{*}{0,1910} \\
\hline & 2. Anêmico/ictérico & 47 & 50 & & 62 & 53 & & 38 & 36 & & 39 & 61 & \\
\hline \multirow{2}{*}{ Fezes } & 1. Normal & 57 & 61 & \multirow{2}{*}{0,4134} & 60 & 60 & \multirow{2}{*}{0,6950} & 68 & 61 & \multirow{2}{*}{$0,0116^{*}$} & 63 & 61 & \multirow{2}{*}{0,6824} \\
\hline & 2. Diarréia & 17 & 13 & & 10 & 12 & & 0 & 6 & & 3 & 4 & \\
\hline \multirow{2}{*}{ Respiratório } & 1. Normal & 71 & 69 & \multirow{2}{*}{0,4672} & 68 & 66 & \multirow{2}{*}{0,1571} & 66 & 64 & \multirow{2}{*}{0,6365} & 62 & 61 & \multirow{2}{*}{0,9822} \\
\hline & 2. Dispnéia & 3 & 5 & & 2 & 6 & & 2 & 3 & & 4 & 4 & \\
\hline \multirow{3}{*}{$\begin{array}{l}\text { Linfonodos } \\
\text { inguinais }\end{array}$} & 1. Normais & 4 & 1 & \multirow{3}{*}{0,2431} & 3 & 0 & & 5 & 2 & & 2 & 3 & \\
\hline & 2. Hipertróficos & 70 & 72 & & 67 & 72 & 0,0758 & 63 & 65 & 0,2525 & 64 & 62 & 0,6359 \\
\hline & 3. Hipotróficos & 0 & 1 & & 0 & 0 & & 0 & 0 & & 0 & 0 & \\
\hline & 1. Ausente & 65 & 61 & & 49 & 39 & & 62 & 46 & & 54 & 55 & \\
\hline Lesão de pele & 2. Presente & 9 & 13 & 0,3554 & 20 & 31 & 0,1485 & 5 & 16 & $0,0045^{*}$ & 10 & 9 & 0,8239 \\
\hline & 3. Em cicatrização & 0 & 0 & & 1 & 2 & & 1 & 5 & & 2 & 1 & \\
\hline
\end{tabular}

${ }^{a}$ Nível descritivo de probabilidade pelo teste de $\chi^{2}$.

Dos 148 leitões utilizados no experimento, $12,12 \%$ e $10,81 \%$, respectivamente no $\mathrm{T}_{1}$ e $\mathrm{T}_{2}$, morreram com diagnóstico da SMD baseado na necropsia, histopatológico e IHQ, não havendo diferença entre os tratamentos. Essa taxa de mortalidade é baixa, considerando que eram leitões com sinais clínicos de SMD. SEGALÉS et al., 2004 verificaram a campo que 70 a $80 \%$ dos leitões com sinais clínicos da SMD chegam a óbito. ZANELLA \& MORÉS (2003) citam que cerca de $50 \%$ dos suínos afetados morrem em menos de oito dias. No exame de necropsia, a ocorrência de úlcera gástrica e dermatite difusa foram observadas apenas nos leitões do $T_{1}$. Na observação dos autores, o fato de retirar os leitões das baias originais e alojá-los em baias separadas, na mesma instalação, aumentou a taxa de sobrevivência nos dois tratamentos, superando as expectativas. Provavelmente, isso ocorreu devido ao alojamento em ambiente melhor, com menor pressão de infecção, lotação adequada, diminuição da competição, fornecimento de ração à vontade e, consequentemente, diminuindo o estresse e os fatores de risco (MADEC, 1999). Como a maioria dos leitões se contaminaram com PCV2 na fase de creche (PUJOLS et al., 2008), é possível que o uso preventivo do plasma suíno spray dry para todos os leitões na fase de creche, por inclusão na ração, seja eficiente na prevenção da SMD. Está é uma hipótese a ser testada, pois a inclusão de plasma spray dry na dieta de leitões desmamados estimula o consumo de alimento, aumenta a taxa de ganho de peso e melhora a conversão alimentar (COFFEY \& CROMWELL, 2001). Ademais, SHEN et al., 2011 verificam que o plasma spray dry é seguro para ser utilizado em suínos, pois apresenta o DNA do circovirose tipo 2 em sua composição, porém não é transmissível quando fornecido para leitões sadio.

\section{CONCLUSÕES}

Os leitões com sinais da SMD que receberam plasma em água acidificada apresentaram 
melhora clínica em relação aos controles apenas no período em que receberam o produto e melhor conversão alimentar nos primeiros 28 dias de experimento. A taxa de mortalidade não foi afetada.

\section{REFERÊNCIAS}

ARAÚJO, L. F.; JUNQUEIRA, O. M.; ARAÚJO, C. S. S. Proteína sangüínea na alimentação de leitões. Suinocultura Industrial, v. 2, p. 27-30, 2002.

COFFEY, R. D.; CROMWELL, G. L. Use of spray-dried animal plasma in diets for weaning pigs. Pig News and Information, v. 22, n. 2, p. 39N-43N, 2001.

EMERGING threats quartely report: pig diseases. Animal Health and Veterinary Laboratories Agency, May $16^{\text {th }}$ 2011. Disponível em: <http://vla.defra.gov.uk/reports/docs/rep_survrep_qtlyp01 11.pdf>. Acesso em: 8 dez. 2011.

HARDING, J. C. S. et al. Postweaning multisystemic wasting syndrome: Epidemiology and clinical presentation. Swine Healtb and Production, v. 6, n. 6, p. 249-254, 1998.

HARRELL, R. J. et al. Effets of animal plasma proteins on intestinal recovery of neonatal pigs infected with rotavirus. FASEB Journal, v. 14, p. A728, 2000.

KIM, J.; CHOI, C.; CHAE, C. Pathogenesis of postweaning multisystemic wasting syndrome reproduced by co-infection with Korean isolates of porcine circovirus 2 and porcine parvovirus. Journal of Comparative Pathology, v. 128, p. 52-59, 2003.

MADEC, F. et al. La maladie de eámaigrissement du porcelet (MAP) en France: aspecs descriptifs, impact en élevage. Journées de la Recherche Porcine en France, v. 31, p. 347-354, 1999.

MORÉS, N. et al. Influência do nível protéico e/ou da acidificação da dieta sobre a diarréia pós-desmame em leitões causada por Escherichia coli. Pesquisa Veterinária Brasileira, v. 10, p. 85-88, 1990.

PUJOLS, J. et al. Lack of transmission of porcine circovirus type 2 to weanling pigs by feeding them spraydried porcine plasma. Veterinary Record, v. 163, p. 536538, 2008.

SAS INSTITUTE INC. System for Microsoft Windows: release 8.2. Cary, 1999-2001. 1 CD-ROM.

SEGALÉS J. Porcine circovirus type 2 (PCV2) infections: clinical signs, pathology and laboratory diagnosis. Virus $\begin{array}{llll}\text { Research. } & 17 & \text { Oct } & \end{array}$ doi:10.1016/j.virusres.2011.10.007.

SEGALÉS, J.; ROSELL, C.; DOMINGO, M. Pathological findings associated with naturally acquired porcine circovirus type 2 associated disease. Veterinary Microbiology, v. 98, n. 2, p. 137-149, 2004.

SHEN, H. G. et al. Opriessnig T. Commercially produced spray-dried porcine plasma contains increased concentrations of porcine circovirus type 2 DNA but does not transmit porcine circovirus type 2 when fed to naive pigs. Journal Animal of Science, v. 89, n. 6, p. 19301938, 2011.

VAN DIJK, A. J. et al. The effect of dietary spray-dried porcine plasma on clinical response in weaned piglets challenged with a pathogenic Escherichia coli. Veterinary Microbiology, v. 84, p. 207-218, 2002.

XAVIER, L. H. Modelos univariado e multivariado para análise de medidas repetidas e verificação da acurácia do modelo univariado por meio de simulação. Piracicaba, 2000. Dissertação (Mestrado) - Escola Superior de Agricultura "Luiz de Queiroz", Universidade de São Paulo, Piracicaba. Disponível em: < http://www.lce.esalq.usp.br/tadeu/LaraHXavier3.pdf >. Acesso em: 8 dez. 2011.

ZANELlA, J. R. C.; MORÉS, N. 2003. Circovirose suína. Concórdia: Embrapa Suínos e Aves, 2003. 11 p. (Embrapa Suínos e Aves. Circular Técnica, 37). 